\title{
GESTAÇÃO, PARTO E PUERPÉRIO: UMA DISCUSSÃO SOBRE TECNOLOGIA, HISTÓRIA E CULTURA ${ }^{5}$
}

Maria Juracy Aires ${ }^{6}$

\section{Resumo:}

Este artigo aborda os aspectos emocionais e culturais inerentes a cada gravidez. Reflete sobre a passividade da parturiente e a possivel relação com os discursos existentes nos planos subjacentes à realidade desse momento, dificultando a reivindicação de melhor atendimento no parto. Aponta para o distanciamento causado pelo progresso tecnológico na área da reprodução humana de suas raízes socioculturais. O trabalho também comenta o alto índice de procedimentos já considerados ineficazes pela Organização Mundial de Saúde e insere a Doula no cenário do parto, resgatando um processo que se dava através de experiências vivenciadas e passadas de mãe para filha, ou através das parteiras.

Palavras-chave: Assistência ao parto; tecnologia; história; cultura.

O fenômeno da gestação, parto e puerpério é da natureza da mulher, que tem a função social e, pode-se dizer "sagrada", de conceber e parir novas criaturas. No entanto, nem sempre essa mulher recebe a merecida atenção, sendo alvo de uma desconsideração que se observa na maioria dos atendimentos à parturiente nos serviços de saúde.

Esse fato se atesta a constante preocupação que pesquisadores de diversas áreas do conhecimento conferem ao tema, delatando tais formas de atendimento. Dentre estes pesquisadores, destaca-se Nogueira, (1994, p.38) que afirma: "A assistência ao parto é a manifestação mais evidente de como uma sociedade considera a mulher, a maternidade e a criança".

Corroborando essa afirmação, o historiador francês Jacques Gélis (apud MOTT, 2002, p.399) escreve: "o nascimento não se restringe a um ato fisiológico, mas testemunha por uma sociedade, naquilo que ela tem de melhor e de pior".

Portanto, segundo Cosminsky, (1978) (apud GUALDA, 2002, p.41), cada sociedade "tem sua maneira peculiar de organizar e moldar a vivência da crise biológica do nascimento". O autor afirma ainda que "o parto constitui um processo de ajustamento às normas socioculturais".

A sociedade atual, que "está organizada em torno de uma ideologia de progresso tecnológico" (FLOYD, p.24), também se encarrega de formar nas pessoas os valores condizentes com essa concepção.

Nesse contexto histórico a biomedicina moderna, arraigada ao conhecimento especializado, procedimentos técnicos e normas de comportamento, treina os profissionais de saúde num modelo essencialmente tecnocrático, cujos princípios básicos, segundo Floyd, são:

5 Parte deste artigo foi apresentado no Encontro Internacional Fazendo Gênero 6 : Saberes Globais/Fazeres Locais, Saberes Locais/Fazeres Globais, promovido pela Universidade Federal de Santa Catarina no período de 10 a 13 de agosto de 2004.

6 Mestre em Tecnologia pelo programa de Pós-Graduação em Tecnologia - PPGTE, da Universidade Federal Tecnológica do Paraná - UTFPR. Pesquisadora do Grupo de Estudos e Pesquisas sobre Relações de Gênero e Tecnologia - GeTec (www.ppgte.cefetpr.brigenero). Rua Atílio Bório, 174, ap.72 - Cristo Rei - Curitiba, Paraná; e-mail: najuha@ terra.com.br; fone (41) 3363-0395. 
1 - Separação mente-corpo.

2 - Considerar o corpo como uma máquina.

3 - Ver o paciente como um objeto.

4 - Distanciamento do médico (de seu paciente).

5 - Diagnóstico e tratamento de fora para dentro.

6 - Organização hierárquica e padronização do cuidado.

7 - Autoridade e responsabilidade inerente ao médico, não ao paciente.

8 - Supervalorização da ciência e da tecnologia.

9 - Intervenções agressivas com ênfase em resultados em curto prazo.

10- A morte como derrota.

11-Sistema guiado pelas ganâncias.

12 - Intolerância a outras modalidades (FLOYD, 2004,p.24).

$\mathrm{Na}$ especialidade obstétrica, esse módelo tem desencadeado reflexões e discussões tanto da área acadêmica, quanto de organizações da sociedade civil. Com esse propósito, mobilizam-se em todo o País várias entidades comprometidas com a assistência ao parto, como organizações não governamentais, núcleos de pesquisa e ativistas feministas. Destes, podem-se citar; a Rehuna (Rede de Humanização do Parto e do Nascimento); Grupo Curumim-Gestação e Parto; Cais do Parto; Rede Feminista de Saúde (Rede Nacional Feminista de Saúde, Direitos Sexuais e Direitos Reprodutivos); entre outros.

Muitos desses trabalhos desembocam no movimento emergente do ideário do atendimento ao binômio mãe/bebê, que é o da Humanização do Parto e do Nascimento no Brasil, também presente em outras partes do mundo, essencialmente onde $o$ atendimento às mulheres privilegia $o$ paradigma tecnocrático. Tal estilo de pensamento, característico da sociedade ocidental moderna, está fundado na crença de que o conhecimento da Biologia, aliada ao avanço tecnológico, é suficientemente eficaz na condução do processo do nascimento.

No entanto, a insatisfação com o atendimento hospitalar/institucional, delatada por meio dos movimentos de mulheres, reconhecidamente problemático por outros atores sociais, aponta uma estreita relação entre as técnicas utilizadas neste atendimento e a chamada "desumanização" das atuais práticas obstétricas. De forma que em muitas regiões do mundo industrializado, o descontentamento com o modo como alguns profissionais assistem os partos está cada vez mais presente.

O choque entre as culturas leiga e obstétrica tem sua base, segundo Davis Floyd, (apud HELMAN, 2003, p.161) na medicina, cujo paradigma "cada vez mais define a saúde e os seus problemas, sobretudo, em termos de disfunção fisiológica".

Ainda, segundo Helman, o conflito oriundo desse choque cultural, isto é, a visão do médico de um lado, e a da mulher de outro, aparece com mais clareza quando se observam as diferenças com que cada um avalia todo o processo. Para o médico, a atenção à gravidez inicia-se no pré-natal e termina com o parto. Ao passo que para a mulher, este bebê representa mudanças profundas em muitos aspectos de sua vida, quais sejam: o status social modificado de "mulher" para o de "mãe"; outras relações sociais etc. Fatos esses que não deixam dúvida de que o nascimento, em todas as sociedades 
humanas, tem um significado que extrapola um evento meramente biológico.

Talvez um dos aspectos que mais fortemente aparece como agressão, além da estrutura física da mulher, com procedimentos dolorosos e invasivos, é no que diz respeito à sua integridade moral e emocional. Conforme argumenta Davis Floyd (apud HELMAN, 2003, p.162), a obstetrícia perpetua no sistema de rituais em torno do parto, valores que "incluem a impotência feminina, [...] a dependência em relação à ciência e à tecnologia [...] e a superioridade das máquinas sobre as crenças individuais."

Atenta à qualidade do atendimento à mulher nos hospitais e maternidades, a Organização Mundial da Saúde (O.M.S.), fundamentada nas melhores evidências disponíveis, classifica em quatro categorias as práticas comuns na condução do parto normal. A publicação, O Guia Prático: Maternidade Segura, 1996, p. 35, classifica as práticas, de acordo com sua utilidade, eficácia e ausência de periculosidade.

Categoria A - práticas demonstradamente úteis e que devem ser estimuladas;

Categoria B - práticas claramente prejudiciais ou ineficazes e que devem ser eliminadas;

Categoria $\mathrm{C}$ - práticas em relação às quais não existem evidências suficientes para apoiar uma recomendação clara e que devem ser utilizadas com cautela até que mais pesquisas esclareçam a questão;

Categoria D - práticas freqüentemente utilizadas de modo inadequado.

$\mathrm{Na}$ categoria "B" estão: o uso rotineiro de enema (lavagem intestinal), a tricotomia (raspagem dos pelos pubianos), a posição supina (deitada de costas), os puxos prolongados e dirigidos; todos identificados como procedimentos causadores de muito mal-estar e desconforto, além da dor.

$\mathrm{Na}$ categoria " $\mathrm{D}$ " tem-se: a restrição hídrica e alimentar - que comprovadamente aumenta a sensação de dor -, a analgesia peridural, o monitoramento eletrônico fetal, o uso de ocitócitos e a episiotomia de rotina ${ }^{7}$.

Procedimento utilizado em quase todos os partos atendidos nos hospitais e maternidades, a episiotomia é um corte feito pelo obstetra na região perineal visando ampliar o canal do parto. As justificativas para esta prática vão desde a prevenção de uma grande laceração, e neste caso, a equipe obstétrica avalia que um corte reto seria preferível; até a crença - sem embasamento científico - de que o parto normal sem a intervenção cirúrgica da episiotomia, alarga a vagina da mulher.

Simone Diniz (2004, p.96) afirma ser justamente por conta da episiotomia que a mulher pode vir a ter sua sexualidade prejudicada. Segundo a autora, "a cicatriz muscular pode afetar posteriormente o prazer sexual e provocar dor durante a penetração". Muitas vezes, reafirma Diniz, é necessário que se faça uma outra cirurgia para corrigir "as seqüelas de uma episiotomia mal costurada e mal cicatrizada".

Quanto à administração de ocitócitos, esta intervenção é agravada por

7 Nos Estados Unidos a episiotomia é realizada em 50 a 90\% das primíparas (O.M.S. Genebra, 1996).

Na Europa é usada em 5 a $30 \%$ dos partos normais. Na América Latina, faz-se episiotomia em quase todos os partos (DINIZ\&DUARTE, 2004, p. 95-96). 
não ter apresentado diminuição considerável da duração do trabalho de parto. Além disso, "mais de $80 \%$ das mulheres achavam que a correção de dinâmica era desagradável e tinha causado um aumento de sua dor" (OMS, 1996, p. 24).

O paradigma proposto pela O.M.S. tem como objetivo a assistência à mãe e ao bebê com o menor número possível de intervenções que seja compatível com a segurança. Isso significa que no parto normal somente uma boa razão será motivo para interferir sobre o processo natural.

Mulheres em atendimento psicológico, quando indagadas sobre as experiências de`satisfação que tiveram no parto, estas não têm relação com ausência total de dor. Ao contrário, essas mulheres se mostram dispostas a sentir alguma dor; o que elas não desejam é que a dor seja insuportável. Quanto a isso, alguns fatores como o comportamento dos profissionais, um ambiente acolhedor e a presença constante de companhia, são apontados por elas como essenciais para que a dor seja amenizada.

Por outro lado, há que se pontuar que em determinadas situações a percepção da dor é comprovadamente aumentada. Os fatores apontados como mais comumente responsáveis pelo aumento da percepção da dor são: medo, estresse, tensão, fadiga, frio, fome, sede, solidão, desamparo social e afetivo, entre outras. Muitas dessas causas de sofrimento estão presentes em atendimentos hospitalares, que não estão sintonizados com a assistência ao parto humanizado.

A antropóloga Dra. Robbie Davies-Floyd comenta em entrevista (Revista Seu Filho e Você, 2002, p.76), que para acontecer o parto humanizado no Brasil, de imediato, é preciso mudar os hospitais; não a arquitetura, mas as atitudes e a filosofia de trabalho. A autora acrescenta que uma das principais mudanças é o fornecimento de informações claras e precisas à mulher acerca do processo do parto. Além disso, é fundamental oportunizar que a parturiente escolha a melhor posição para dar à luz, tenha direito de ingerir líquidos durante o trabalho de parto, entre outras medidas que Ihe proporcionem conforto.

Dr. Moysés Paciornik, médico ginecologista formado há 68 anos, é militante e precursor do parto de cócoras no Brasil. Em entrevista que nos foi concedida em 05.07.2004, o obstetra compara o mecanismo do parto ao ato natural e fisiológico da evacuação:

No trabalho de parto e na evacuação, o mecanismo é exatamente igual. Nenhuma mulher admite que precisando evacuar, estando sozinha no mato ou no campo ou numa praia sem ninguém enxergar, deita e levanta as pernas pra evacuar. Instintivamente ela se posiciona muito corretamente. Separa as pernas, fica de cócoras, faz força. Não precisa ensinar, [...] é instintivo, se ninguém atrapalhar, ela tem o parto muito corretamente.

Desde os primórdios da humanidade, sempre nasceram crianças, e o processo do parto e os cuidados à parturiente sempre fizeram parte da vida das pessoas e eram tratados como um evento além de fisiológico, também cultural e social.

Prática tão antiga quanto o é a humanidade, a parturição foi, até o século XIX, "um assunto de mulheres" e, sobretudo, um evento sócio-histórico 
importante, já que "tanto na sociedade grega quanto na romana a importância da mulher era medida por sua capacidade em gerar herdeiros saudáveis" (MARTINS, 2000, p.64).

Na história do atendimento à gestante e parturiente, verificamos que até o século XVII, aproximadamente, as mulheres pariam seus filhos exclusivamente entre elas. Observando umas às outras e/ou com a vivência do próprio parto, as mulheres - e também homens, pela necessidade de atender uma emergência -, apropriavam-se do conhecimento de partejar. Pelo intercâmbio de experiências vivenciadas e passadas de mãe para filha, ou através de parteiras, é que se construía, oralmente, todo o conhecimento do processo de nascer.

Nesse sentido, talvez a obstetrícia de hoje seja tributária do conhecimento tecnológico desenvolvido há milênios por parteiras tradicionais. Composta pelo arsenal de técnicas, artefatos, comportamentos, atitudes, crenças, etc., esta tecnologia foi, lenta e gradativamente, sendo construida na observação, experimentação e, sobretudo, na vivência histórica e sociocultural.

O conhecimento de partejar, portanto, não obstante a participação pontual dos homens -, pode-se dizer que é, originalmente, transmitido e enriquecido através das culturas entre mulheres. Um conhecimento que, distintamente do modelo acadêmico, vem associado a uma construção social e cultural, onde os rituais e a tradição representam o seu arcabouço principal. A literatura aponta que é somente com o surgimento das primeiras civilizações da Antiguidade e o aumento da população, após a Idade Média, que são registradas a existência de corporações para desempenhar ações de saúde e formação profissional (PIRES, 1989).

Assim, dentro de uma mesma comunidade, as mulheres se autoajudavam e a partir desta proximidade com o fenômeno da parturição adquiriam o aprendizado necessário para atender o parto. De sorte que uma pessoa amiga, inclusive o marido ou companheiro, que estivesse presente prestava auxílio à parturiente (PIRES, 1989).

Mesmo atualmente, muitas mulheres, por opção, ou por falta de acesso a um serviço "oficial" de saúde, escolhem a própria casa e a companhia de amigos e familiares para viver o processo do parto (Fig.1).

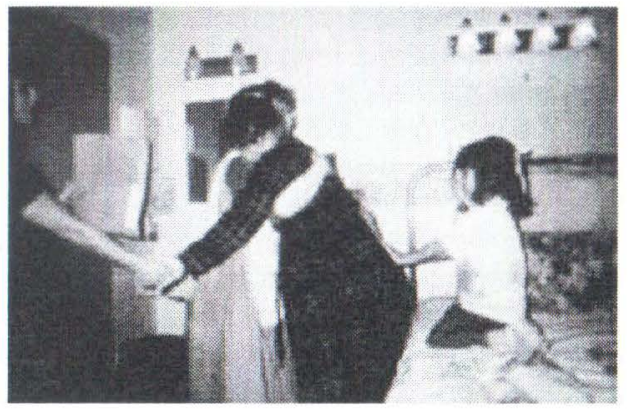

Fig.1: Trabalho de parto no ambiente domiciliar.

Fonte: http://www.motherfriendly.org 
Consta que a inserção masculina no cenário do parto somente aconteceu quando um médico emprestou seu braço forte às parteiras, para atender o parto de Louise de Lavallière, amante de Luiz XIV. Foi a primeira vez que um homem assistiu uma mulher em suas dores e pela primeira vez, uma mulher confiou a um homem o fruto de suas entranhas (SZEJER, 1997).

A partir daí, a obstetrícia engajou-se no progresso tecnológico usando artefatos como a informática e a ultra-sonografia, dentre outros, para desvendar "[...] os mistérios da vida que, por trás da parede abdominal das parturientes, côntinua a se desenvolver do mesmo modo que nos primeiros dias da humanidade" (SZEJER, 1997, p.118).

Assim, a transparência hoje oferecida pela alta tecnologia permite uma previsibilidade cada vez maior, sendo possível estimar a data provável do parto, e, para alguns obstetras, também afirmar, com razoável antecedência, que o parto somente será possível através da cesárea. Constituindo um fator preocupante para a O.M.S., os riscos de morbi-mortalidade na cesárea são aumentados em dez vezes, tanto para a mãe quanto para o bebê, quando comparados ao parto vaginal (FERREIRA, 2003).

No entanto, talvez por desconhecerem esses riscos e não serem informadas durante o pré-natal, as mulheres, "com anuência do médico, porém nem sempre com necessidade real do ponto de vista fisiológico, [...] marcam dia e hora para o rebento vir ao mundo. [...] por comodidade, para evitar o sofrimento físico ou mesmo para satisfazer caprichos" (Revista Veja, maio/2004, p.65).

Apesar de o trabalho de parto e o parto serem, realmente, dolorosos, há que se relevar que esta idéia é intensificada, especialmente pela mídia televisiva. São recorrentes as cenas apelativas sugerindo que as dores do parto são insuportáveis e, sobretudo, que o parto vaginal é um evento quase animalesco. As matérias jornalísticas e as telenovelas, geralmente, abordam a temática do parto vaginal de forma sensacionalista, supervalorizando elementos como perigo, tensão, dor e sofrimento (AIRES, 2005).

No entanto, a obstetra Stella B.Ferreira (2003) 'desempodera' esse imaginário dizendo que "a dor do parto é uma dor curta, finita, [...] existem recursos científicos que permitem amenizar enormemente." Enquanto que numa cesárea "absolutamente sem complicações", a mulher vai sentir uma outra dor que será: "intensa por três dias, profundamente desagradável por dez dias e uma dor que a manterá em repouso por 6 a 8 semanas", e que então, substituir o parto normal por uma cesárea, sem indicação real, "é uma troca que freqüentemente não vale a pena!"

Vale lembrar que uma das características do homem moderno é a sua intolerância ao sofrimento e que a dor, apesar de ser um mecanismo saudável, "sugere sempre um acontecimento negativo - uma experiência desagradável" (FIGUEIRÓ, 2000, p.15). Porém, no caso específico da dor do parto, não se pode deixar de considerar que, além dos aspectos pessoais, psicológicos e culturais, essa também se fundamenta em raízes inconscientes e arcaicas.

Os discursos que fervilham no plano subjacente à realidade têm suas origens nos arquétipos dos mitos que tecem as figuras do feminino e da maternidade na sociedade ocidental. Essas figuras são revestidas de aura simbólica, desde o modelo erótico da mulher do Paraíso que se torna mãe à 
custa de dores, até o modelo da maternidade de uma virgem, cujo amor é puro e consagrado (MALDONADO, 2000). Como o diz Badinter (1985, p.9), "[...] a maternidade é, ainda hoje, um tema sagrado". Tornando-se "difícil questionar o amor materno e a mãe permanece em nosso inconsciente coletivo identificado a Maria, símbolo do indefectível amor oblativo".

Talvez essa atitude identificatória seja a responsável pela passividade das parturientes que assim, não reivindicam seus direitos, aliás, referendados nos manuais de atendimento humanizado, editados pelo Ministério da Saúde. Isso é ainda mais grave, quando se trata de mulheres de baixa renda, por falta de acesso às informações desse tipo e pouco conhecimento sobre suas reais condições físicas.

Assim, muitas mulheres em trabalho de parto atendem a comandos da equipe de saúde, como os de "fazer força", "respirar corretamente", "não chorar", ou "não gritar", assumidos com a humildade e a obediência de uma santa, como a que concebeu e pariu, resignadamente, sem reclamar. Sofrimentos de toda ordem geram sentimentos tais que a mulher, refém de idéias culturalmente elaboradas - entre elas o inquestionável amor materno -, não ousa revelar suas dores nem tampouco as emoções ambíguas com relação ao bebê.

Após o advento dos analgésicos e anestésicos, costuma-se recorrer a eles para bloquear as dores de qualquer natureza. Porém, no caso das parturientes, estes medicamentos deveriam ser utilizados com parcimônia. É o que afirma Kitzinger (1987, p.6):

Todas as drogas dadas à mãe penetram na corrente sangüinea e cruzam a placenta em várias proporções na direção do feto [...] dadas em grandes quantidades, afetam os bebês, que ficam moles e flácidos, jazendo inertes ao invés de olhar em torno, alertas, como faz um recémnascido sadio; não acordam para se alimentar nem sugam vigorosamente quando colocados ao seio, e, ao nascer, demoram mais tempo para respirar.

Tornam-se então oportunas as técnicas de alívio não-farmacológico da dor, executadas pela Doula ${ }^{8}$, por melo de massagens e escuta atenta às queixas da parturiente. Oferecer-Ihe companhia ininterrupta, utilizar técnicas de relaxamento, descontração, entre outras atitudes de conforto, podem significar uma analgesia também eficaz na redução das dores do parto.

Dr.Moisés Paciornik, médico obstetra já citado neste trabalho, partilha da idéia de que a parturiente se beneficia com a presença da(o) acompanhante: "[...[ a mulher deve sempre estar acompanhada por alguém que lhe dê segurança. Antigamente as Doulas eram as mães, irmãs, depois quando começou o parto em maternidades, tudo esterilizado então impediu a entrada de parentes e qualquer pessoa estranha ao corpo médico e a mulher fica isolada, abandonada".

8 Doula é palavra grega que significa aquela que serve a outra mulher, referindo-se à assistência prestada por uma mulher especialmente treinada para assistir a outra no período perinatal. Seu trabalho consiste em orientar e ajudar a parturiente a encontrar posições confortáveis para o parto, mostrar formas eficientes de respiraçāo, relaxamento, e, sobretudo, aplicar técnicas de alívio não-farmacológico da dor. 
Arriscamos dizer que a analgesia solicitada pela mulher na hora das dores do parto, não se restringe às dores físicas, mas também às dores do medo, da insegurança, da solidão. Dores estas que, certamente, serão amenizadas com a presença de alguém que ouça suas angústias e ofereça apoio emocional na passagem desse ritual, que sempre está permeado de incertezas e expectativas. Grande parte desta insegurança pode ser justificada pela absoluta imprevisibilidade - muitas vezes percebida inconscientemente com relação à mudança abrupta advinda com esta nova etapa de sua vida: a de ter um filho para amar e cuidar.

$\mathrm{Na}$ literatura que aborda o processo do nascimento, o momento do parto é vivido pela mulher como um dos mais importantes e inesqueciveis de toda a sua vida. De fato, pode-se verificar que a maioria das mulheres consegue lembrar de detalhes desta experiência - certamente os mais significativos para ela. Algumas fazem menção a cheiros, a toque de pele, a barulho externo, ao choro do bebê, a palavras ditas por alguém e outras particularidades, que em outros momentos passariam despercebidos.

Reminiscências tão vivas de um evento que, em alguns casos, se passou há mais de cinqüenta anos, apontam para uma apurada percepção sensorial, uma sensibilidade muito mais aguçada naquele exato momento, como se todo o seu "ser" estivesse "plugado" com o ambiente ao seu redor.

Ao final dos anos 1960 e início dos anos 1970, a pesquisadora Penny Simkin estudou em vinte mulheres, os impactos referentes à vivência do nascimento dos seus filhos, depois de passados 15 a 20 anos da ocorrência do parto normal. As mulheres afirmaram que as lembranças mais vívidas estavam associadas a lembranças das palavras e ações das pessoas que thes prestaram atendimento durante o parto (BIRTH 18:4, Dezembro, 1991. in: PASCALI-BONARO, 2002).

À luz destas lembranças, gostariamos de apontar o caráter institucional/operacional da atenção ao parto e nascimento, realizado num modelo que reifica a eficácia da técnica e da tecnologia. Embora o parto e o nascimento transcorram, desde sempre, dentro de uma universalidade físicobiológica, se considerados os sujeitos envolvidos: a mãe, o pai, o bebê, a familia, a comunidade, a sociedade; talvez seja reducionista uma visão meramente mecanicista de um evento que é tão divinizado para alguns, sublime para outros, e marcante na vida de todos.

A guisa de conclusão, gostariamos de provocar uma reflexão acerca deste evento cujas raizes históricas e socioculturais apresentam-se tão fortemente marcadas. Se consideradas estas especificidades e, sobretudo, que cada parto é diferente do outro, mesmo para a mesma mulher, temos que admitir que a atual atenção prestada ao processo do nascimento carece de uma dose generosa de subjetividade. Indagamos também se a equipe de profissionais; os artefatos; os procedimentos; as normas; as rotinas; não estariam, literalmente, roubando a cena dos verdadeiros atores deste acontecimento. 


\section{Referências:}

BADINTER, Elisabeth. Um Amor Conquistado - O mito do amor materno. Rio de Janeiro: Nova Fronteira, 1985.

FERREIRA, Stella B. In: Por que Cesárea? - víDEO. Dir. de Â. Mascelani e M. Lane. Recife, Rio de Janeiro, Curumim: UNICEF, 2003. $20 \mathrm{~min}$.: son; color; 12mm; VHS-NTSC. FIGUEIRÓ, João Augusto. A dor. São Paulo: Publifolha, 2000.

FLOYD, Robbie Davis. Del Médico al Sanador. Buenos Aires: Creavida, 2004.

GUALDA,Dulce M.R.Eu conheço minha Natureza:a expressão cultural do parto..Curitiba: Maio: 2002.

HELMAN, Cecil G. Cultura, Saúde \& Doença. Porto Alegre: Artmed, 2003.

KITZINGER, Sheila, A experiência de dar à luz.. São Paulo: Martins Fontes, 1987.

MALDONADO, M.Tereza.Psicologia da Gravidez. São Paulo: Saraiva, 2000.

MARTINS, Ana Paula Vosne. A medicina da mulher: visões do corpo feminino na constituição da obstetrícia e da ginecologia no século XIX. Tese (Doutorado). Campinas, 2000.

MOTT, Maria Lucia. Dossiê Parto, Estudos Feministas, UFSC/CFH/CCE, v. 10, n. 2/2002.

NOGUEIRA, Maria Inês. Assistência Pré-Natal: Prática de Saúde a Serviço da Vida. São Paulo: Hucitec, 1994.

ORGANIZAÇÃO MUNDIAL DE SAÚDE. Assistência ao parto normal: um guia prático. Relatório de um grupo técnico. Genebra, 1996.

PASCALI-BONARO, Debra, B. Ed. CBE. CD (DONA). Novos Conceitos na Assistência ao Parto: Treinamento de Doulas para Apoio no Trabalho de Parto, 2002 - Mimeo.

PIRES, Denise. Hegemonia Médica na Saúde e a enfermagem - Brasil: 1500 a 1930. São Paulo: Cortez, 1989.

SZEJER, Myriam. Nove Meses na vida da mulher - uma abordagem psicanalítica da gravidez e do nascimento. São Paulo: Casa do Psicólogo, 1997.

ZAKABI, Rosana, Bebê com hora marcada. Revista VEJA, maio/2004, p.65. 